\title{
A SURVEY OF SOME BOUNDS FOR GAUSS' HYPERGEOMETRIC FUNCTION AND RELATED BIVARIATE MEANS
}

\author{
Roger W. Barnard, Kendall C. Richards and Hilari C. Tiedeman
}

Abstract. We give an expository summary of a collection of inequalities involving Gauss' hypergeometric function ${ }_{2} F_{1}$ and the closely-related power mean (and certain other bivariate means). Two conjectures involving simultaneous sharp bounds for the hypergeometric function are included. Sharpness for the corresponding zero-balanced case is observed.

Mathematics subject classification (2010): 33C05, 33-02.

Keywords and phrases: Gauss' hypergeometric function, Hölder/power mean, arithmetic-geometric mean, logarithmic mean, Stolarsky mean.

\section{REFERENCES}

[1] G. Almkvist And B. Berndt, Gauss, Landen, Ramanujan, the aritmetic-geometric mean, ellipses, pi, and the Ladies Diary, Amer. Math. Monthly, 95 (1988), 585-608.

[2] G.D. Anderson, R.W. Barnard, K.C. Richards, M.K. Vamanamurthy, and M. VuoriNEN, Inequalities for zero-balanced hypergeometric functions, Trans. Amer. Math. Soc., 347 (1995), 1713-1723.

[3] H. AlzER H. AND S.-L. QIU, Monotonicity theorems and inequalities for the complete elliptic integrals, J. Comput. Appl. Math., 172 (2004), 289-312.

[4] R.W. BARNARD AND K.C. RICHARDS, On inequalities for hypergeometric analogues of the arithmetic-geometric mean, J. Inequal. Pure Appl. Math., 8, 3 (2007), Article 65, 5 pp.

[5] R.W. Barnard, K. PearCe, AND K.C. Richards, An inequality involving the generalized hypergeometric function and the arc length of an ellipse, SIAM J. Math. Anal., 31 (2000), 693-699.

[6] J.M. BorWein AND P.B. BorweIn, Pi and the AGM, Wiley, New York, 1987.

[7] J.M. BORWEIN AND P.B. BoRWEIN, Inequalities for compound mean iterations with logarithmic asymptotes, J. Math. Anal. Appl., 177 (1993), 572-582.

[8] J.M. Borwein, P.B. Borwein, And F. Garvan, Hypergeometric analogues of the arithmeticgeometric mean iteration, Constr. Approx., 9 (1993), 509-523.

[9] P.S. Bullen, Handbook of Means and Their Inequalities, Kluwer Academic Publishers, Dordrecht, 2003.

[10] B.C. CARLson, Some inequalities for hypergeometric functions, Proc. Amer. Math. Soc., 16 (1966), 32-39.

[11] B.C. CARLSOn And M. Vuorinen, An inequality for the AGM and the logarithmic mean, SIAM Rev., 33 (1991), 655.

[12] H. KAZI AND E. Neuman, Inequalities and bounds for elliptic integrals, J. Approx. Theory, 146, 2 (2007), 212-226.

[13] E. Neuman And J. SÁndor, Inequalities involving Stolarsky and Gini means, Math. Pannon., 14, 1 (2003), 29-44.

[14] Z. PÁLES, Inequalities for differences of powers, J. Math. Anal. App., 131 (1988), 271-281.

[15] K.C. RICHARDS, Sharp power mean bounds for the Gaussian hypergeometric function, J. Math. Anal. Appl., 308 (2005), 303-313.

[16] N.M. Temme, Special Functions: An Introduction to the Classical Functions of Mathematical Physics, Wiley Interscience, New York, 1996. 
[17] H.C. Tiedeman, Means are more than average, Southwestern University Honors Thesis, Kendall Richards: Thesis Advisor (2007).

[18] M.K. Vamanamurthy And M. Vuorinen, Inequalities for means, J. Math. Anal. Appl., 183 (1994), 155-166.

[19] M. VuORINEN, Hypergeometric functions in geometric function theory, in: Proc Special Functions and Differential Equations, K.R. Srinivasa, R. Jagannthan, G. Van der Jeugy (Eds.), Allied Publishers, New Delhi, 1998. 